\title{
Principio de legalidad y complemento en la norma primaria en el delito de omisión de agente retenedor, consideraciones sobre la sentencia de la Corte Suprema de Justicia de 10 de junio de 2015, radicado 41.053, ponente Eugenio Fernández Carlier
}

Ricardo Echavarría Ramírez*

\section{Hechos relevantes}

Los hechos que dan lugar a la investigación y posterior condena, se fundan en que el señor N, a nombre de la sociedad FCE Ltda., omite el pago de las sumas retenidas por concepto de retención en la fuente $y$, adicionalmente, realiza un pago inferior al debido por concepto de impuesto a las ventas ${ }^{1}$.

Los hechos materia de proceso fueron puestos en conocimiento de la autoridad judicial competente por parte de la Dirección de Impuestos y Aduanas Nacionales.

* $\quad$ Profesor del área en Derecho penal, Universidad EAFIT. Este trabajo se realiza en el marco del proyecto "La protección a la hacienda pública en el Derecho Penal colombiano", de la convocatoria de proyectos con financiación interna - 2015 Código 621 - 000100 de la Universidad EAFIT, que se desarrolla bajo la dirección del profesor Ricardo Echavarría Ramírez.

1 " (...) presentó las declaraciones de Impuesto a las Ventas (IVA) correspondientes a los periodos 01 al 05 de 2004, pero que luego de ser revisadas por esa entidad oficial generaron un mayor valor a pagar en cuantía que ascendió a $\$ 48.726 .000$, además, omitió consignar las sumas retenidas por concepto de RETEFUENTE de los períodos $8^{\circ}$ y $9^{\circ}$ de la misma anualidad, por valor de $\$ 3.665 .000,00 "$ ", sentencia de la Corte Suprema de justicia de 10 de junio de 2015, radicado 41.053, ponente Eugenio Fernández Carlier, p. 2. 


\section{Aspecto jurídico considerado en la sentencia}

Son tres los elementos objeto de análisis en la sentencia: el primero está referido a la incompleta motivación del fallo, así como la violación al principio de investigación integral. El segundo trata sobre la violación al principio a la defensa y la falta de defensa técnica. El tercer y último aspecto en el análisis por parte de la Corte, considera la posible violación a la ley sustancial, como consecuencia de la indebida aplicación del delito de omisión de agente retenedor.

\section{Argumentos de las partes}

\section{Tesis del recurrente}

El recurrente solicita que se case la sentencia con fundamento en la vulneración de las garantías al debido proceso, el derecho a la defensa y, finalmente, por la violación de la ley sustancial, tanto de forma directa como indirecta.

La afectación a la garantía al debido proceso la refiere el recurrente a la indebida motivación de la sentencia de primera instancia, así como la violación al principio de la investigación integral, lo cual se expone fundamentalmente en los cargos primero y segundo subsidiario. La indebida motivación del fallo de primera instancia, lo que a su juicio convierte el proceso en uno de "única instancia", lo justifica el demandante aduciendo que en la audiencia pública se planteó la nulidad del proceso y la infracción del principio de investigación integral, sin embargo tales reproches sólo encontraron respuesta en la sentencia de segunda instancia.

En lo que toca con la infracción al principio de la investigación integral, tal y como se expone en el segundo cargo de casación (subsidiario), la refiere el recurrente en que no se practicaron pruebas que estaban directamente relacionadas con los hechos materia de proceso, que de practicarse habría conducido a una solución diferente de la sentencia de condena².

La violación al derecho a la defensa y de la falta de defensa técnica, tal y como se exponen en los cargos tercero y cuarto (subsidiarios), se justifican en la falta de notificación de la resolución de acusación ${ }^{3}$ y en la pasividad en el ejercicio de la

2 "Agrega que la Fiscalía hubiera podido establecer la relación de compras y proveedores suministrada por $L$ ante la DIAN que justificaban los descuentos por concepto de costos realizados y consignados en las declaraciones privadas, lo que habría permitido corroborar la atipicidad del comportamiento y arribar por ende a un fallo absolutorio", Ibíd., p. 7.

3 "Denuncia que la resolución de acusación no fue notificada personalmente al procesado ni a su defensor, y sólo obra una constancia secretarial de habérsele enviado al profesional, vía fax, tal proveído, pero sin poder establecer si ello efectivamente ocurrió, pues no reposa en el 
defensa en razón de la incapacidad, por razón de quebrantos de salud del defensor, de atender adecuadamente la labor de defensa ${ }^{4}$.

En los cargos quinto y sexto (subsidiarios) se expone lo relativo tanto a la violación directa como a la violación indirecta de la ley sustancial. En relación con lo primero, esto es, la violación directa a la ley sustancial, el cargo se justifica en la incorrecta interpretación y aplicación del delito de omisión de agente retenedor, como quiera que el delito debe concretarse en la omisión en el pago por concepto de dinero efectivamente recaudado y no, como se deriva de las sentencias condenatorias, de imputar tal omisión a un monto o valor no recaudado sino determinado con fundamento en la liquidación oficial realizada por la DIAN, pues en dicha liquidación no se imputa "al monto del impuesto a pagar las deducciones por costos hechas previamente por el contribuyente, lo que apareja un mayor valor a tributar"5. La interpretación de instancia conduce a una afectación a los principios de legalidad y tipicidad, como quiera que tiene lugar una aplicación analógica in malam partem, dado que aplica un criterio tributario para acreditar una exigencia de la tipicidad del delito de omisión de agente retenedor como es la "real apropiación como condición para predicar la adecuación típica"6.

La violación indirecta de la ley sustancial, sostiene el recurrente, tiene lugar en que se efectúo un falso juicio de identidad en los recibos de pago por conceptos de IVA y Retención en la fuente, los que adecuadamente entendidos habrían conducido bien al reconocimiento de la extinción de la acción penal por pago, bien a cuestionar la recaudación de los impuestos por razón del IVA?.

expediente recibo o memorial del abogado acerca de haber tenido conocimiento de la decisión", Ibíd., p. 7.

4 "Con tal recuento, señala que fue evidente la pasividad defensiva a lo largo del diligenciamiento, lo cual incidió en que únicamente obrara la denuncia penal y la indagatoria del incriminado, sin haber mediado alguna controversia al respecto, por lo que insta la declaración de nulidad a partir del traslado del aludido artículo 400 de la normatividad adjetiva que rigió el asunto", Ibíd., p. 9.

5 Ibíd., p. 9. Adicionalmente, se indica en el cargo que "En criterio del demandante, el tipo penal se edifica respecto de dineros efectivamente recaudados, como lo señaló la Corte Constitucional en sentencia C-009 de 2003, y en manera alguna por el no pago de una liquidación oficial de la DIAN, en la cual no se han reconocidos costos, descuentos y deducciones realizados en la previa declaración privada", Ibíd., p. 10.

6 Ibíd., p. 10.

7 "Presenta un falso juicio de identidad en los recibos de pago oficial de impuestos periodos 08 y 09 de 2004 por concepto de Retención en la Fuente los cuales fueron realizados por su asistido el 2 de octubre de 2009 saldando la deuda por ese concepto con la DIAN, cuando el Tribunal consideró que tales pagos sólo se referían a los intereses, porque de haberlos apreciado en su real dimensión habrían permitido aplicar la extinción de la acción penal por el pago, prevista en 


\section{Concepto del Ministerio Público}

El Ministerio Público concluye que no debe casarse el fallo, como quiera que no es posible advertir la afectación a ninguna de las garantías que, a juicio del recurrente, se vulneran. Así, en punto con la incompleta motivación e infracción del principio de investigación integrar, afirma que las alegaciones de la defensa encontraron adecuada respuesta, si bien no en primera instancia, si en segunda instancia, lo que "subsana" tal irregularidad. Adicionalmente, la práctica de las pruebas que habrían podido modificar la solución del caso no merecen, a juicio de la agencia del Ministerio público, peso suficiente para dar soporte a la violación del principio de investigación integral, a más de considerar que la práctica de tales pruebas no habrían modificado el resultado del proceso, aduciendo para ello que "la DIAN, dentro de su órbita de competencia, realizó un proceso administrativo que finalizó con las liquidaciones oficiales de impuesto sobre las ventas realizadas en el año 2006 sin que las mismas fueran objeto de controversia por parte del acusado"8.

En lo relacionado con la violación al derecho a la defensa y a la falta de defensa técnica, no encuentra motivo alguno el Ministerio Público que permita sostener tal afectación, puesto que la defensa se notificó por conducta concluyente surtida mediante "la constancia secretarial ante la llamada telefónica hecha al defensor y el envió por fax de la providencia"9; además, porque en cualquier caso "el defensor tuvo oportunidad de conocer su contenido y ninguna objeción puso de presente"10. En lo que toca con la falta de defensa técnica, ésta no se encuentra justificada por parte de la defensa" $a^{11}$, adicionalmente, aduce el Ministerio Público que "la simple enunciación de la pasividad del defensor no basta por sí sola para comprometer la legalidad del proceso"12.

el parágrafo del citado artículo 402 del estatuto sustantivo. Denuncia también un falso juicio de identidad de los recibos de pago de impuestos oficiales de revisión del 25 de abril de 2006 número 110642006000034, 28 de marzo de 2006 identificados con los Nos. 110642006000014110642006000016-110642006000013-110442006000015, al distorsionar el juzgador que con ellos el procesado había recaudado los impuestos de IVA determinados en las declaraciones oficiales", Ibíd., pp. 10 y 11.

8 Ibíd., pp. 14 y 15.

9 Ibíd., p. 15.

10 Ibíd., p. 15.

11 “En relación con la inactividad del defensor, señala que el casacionista no explicó de qué manera ello tuvo incidencia en el núcleo esencial de esa garantía, máxime que el derecho de contradicción no se ejerce únicamente en el momento de la aducción del medio probatorio al proceso, sino también en cualquier otra etapa a través de la crítica probatoria, en los alegatos o en los recursos", Ibíd., p. 15.

12 Ibíd., p. 16. 
254 Principio de legalidad y complemento en la norma primaria en el delito de omisión de agente retenedor, consideraciones sobre la sentencia de la corte suprema de justicia de 10 de junio de 2015 - Ricardo Echavarría Ramírez

Finalmente, en lo relativo a la violación de la ley sustancial, a juicio del Ministerio Público ni existe elemento de juicio que permita dudar de la realización de la conducta típica, cual es la omisión en la consignación del dinero adeudado, ni en la indebida interpretación o tergiversación de los recibos de pago, tal y como expone el casacionista ${ }^{13}$.

\section{Consideraciones de la Corte}

La Corte casa parcialmente la sentencia y declara una nulidad parcial de la misma, con fundamento en dos razones: la violación directa de la ley sustancial y la falta de motivación de la sentencia de instancia. En el primer caso, esto es, la violación de la ley sustancial, considera la Corte que se presenta una afectación al principio de legalidad por razón de la aplicación analógica in malam partem al momento de acreditar uno de los elementos del tipo penal de omisión de agente retenedor ${ }^{14}$.

En lo relativo al segundo aspecto que ocupa la atención de la Sala de Casación Penal, esto es, la falta de motivación, ésta efectivamente es relevante al punto de poder afirmarse que el debido análisis de los elementos de juicio que en su momento expuso el recurrente en el curso del proceso, inciden directamente en los presupuestos de la responsabilidad penal.

Frente a los dos temas que ocupan la atención de la Sala, comienza la Corte por el cargo quinto, referido a la violación directa de la ley sustancial, en la medida en que la estimación del cargo lleva aparejado el reconocimiento de la atipicidad del comportamiento de $\mathrm{N}$ en relación con la condena por la omisión en el pago del Impuesto a las Ventas (IVA). Como se indicó, la violación directa de la ley sustancial se justifica en que la aplicación e interpretación que del delito de omisión de agente retenedor se realiza en la sentencia de instancia comporta un desconocimiento

13 "Acerca del alcance interpretativo del artículo 402 del Código Penal, afirma que el demandante no debió cuestionar los hechos ni las conclusiones probatorias y que aquí el juzgador no advirtió duda que el procesado, teniendo la obligación de hacerlo, no consignó los dineros correspondientes al IVA y por ello debía responder penalmente", Ibíd., p. 16. Adicionalmente, también la siguiente consideración del Ministerio Público: "Para el Procurador Delegado, los argumentos del censor no permiten entrever que los funcionarios de instancia al analizar los recibos de pago de impuestos hubieran desdibujado, tergiversado o cercenado su contenido, ni de tales documentos se desprende que en verdad el acusado no hubiere recaudado los dineros", Ibíd., p. 16.

14 "Sin embargo, la Corte en el caso de la especie no puede avalar tal postura, porque contraviene el principio de estricta tipicidad -a través del cual se realiza y desarrolla el principio de legalidad-, como definición abstracta e hipotética que hace el legislador de las conductas que considera dignas de reproche y por lo tanto merecedoras de pena", Ibíd., p. 27. 
del principio de legalidad, por razón de la aplicación analógica in malam partem, dado que uno de los elementos constitutivos del delito, cual es la efectiva o real recaudación del dinero que por obligación legal debe consignar por IVA, no se acreditó efectivamente sino que el monto deriva de la liquidación oficial realizada por la DIAN y del desconocimiento, por vía de sanción, de los valores que previamente fueron declarados por el contribuyente en su declaración ${ }^{15}$.

Para decirlo en otros términos, parte la Corte de reconocer, tal y como se desprende de la sentencia C-009 de 2003, que el delito de omisión de agente retenedor exige la efectiva recaudación de las sumas que por concepto de IVA deben ser pagadas. En consecuencia, este elemento del delito no se acredita cuando no se haya recaudado el dinero 0 , como en el caso objeto de estudio en esta sentencia, cuando tal suma de dinero objeto del impuesto se acredite mediante la liquidación oficial de la DIAN en la que, por aplicación de la sanción prevista en el artículo 651 del Estatuto Tributario, se desestiman los valores cuantificados por el contribuyente en su declaración privada y se desconocen por esto los valores descontables que éste presentó en su correspondiente declaración ${ }^{16}$.

En síntesis, señala la Corte que la fuente de la obligación cuyo incumplimiento se sanciona por vía del delito de omisión de agente retenedor es la obligación tributaria sustancial, la cual se origina al realizarse el presupuesto establecido en la ley como generador del impuesto, pero en ningún caso por vía de la sanción establecida en la ley tributaria ${ }^{17}$. Cabe decir, finalmente, que la decisión de casar parcialmente la sentencia y, con ello, la absolución del recurrente queda referida única y exclusivamente a la condena por razón del impuesto a las ventas, pues fue en relación con este impuesto que se presenta la aplicación analógica in malam partem que se reprocha en la sentencia.

Ahora, en lo que toca con la nulidad parcial del fallo referida en este caso a la condena por la omisión en el pago de la Retención en la fuente, la Corte manifiesta

15 "En este caso surgió un mayor valor por concepto de impuesto sobre las ventas, pero como lo señala el censor, no fue porque probatoriamente se hubiera acreditado el real recaudo del contribuyente, sino que fue producto de una ficción jurídica legalmente establecida de no dar por ciertos los valores consignados por el contribuyente cuando se consideran sus explicaciones extemporáneas, erróneas o sin soporte, como sanción administrativa prevista en el Estatuto Tributario", Ibíd., p. 29.

16 "La cifra cuantificada finalmente por la DIAN no obedeció a la acreditación efectiva de sumas recaudadas, sino que ante la incertidumbre generada por no haber demostrado FCE Ltda., con documentos y soportes idóneos el total de ventas netas, los impuestos descontables y las sumas que por retención por IVA fueron hechas durante los periodos $1^{\circ}$ al $5^{\circ}$ de 2004 , le fueron desconocidos esos valores inicialmente reportados en su declaración privada", Ibíd., p. 28.

17 "El hecho generador de la obligación es el presupuesto establecido en la ley cuya realización origina el nacimiento de la obligación a cargo del contribuyente, de ahí que la sanción no pueda asimilársele a ella, porque solamente es la consecuencia de su incumplimiento", Ibíd., p. 25. 
que no se dio una respuesta a los argumentos de la defensa del recurrente, lo que efectivamente provoca la falta de motivación que se alega ${ }^{18}$. Además de falta de motivación, se considera en el fallo de la Corte que los temas propuestos por el recurrente, y que no encontraron debida respuesta, se dirigen a un aspecto central en punto a la posible responsabilidad penal, como quiera que se refieren a la posible exoneración de responsabilidad penal por pago ${ }^{19}$. Adicionalmente, considera la Corte que se dejó de considerar en instancia el efecto que en la retención en la fuente tiene la modificación del impuesto a las ventas realizada por al DIAN, lo cual es un elemento de juicio añadido para sustentar el reconocimiento del cargo de falta de motivación.

En consecuencia con el reconocimiento de la falta de motivación, determina la Corte declarar la nulidad parcial desde el fallo de primera instancia de forma que se de respuesta a los argumentos de la defensa ${ }^{20}$.

\section{Comentarios sobre la sentencia}

El fallo, como ya se indicó, plantea dos soluciones diferentes en función del reconocimiento por parte de la Corte de dos de los argumentos presentados por el recurrente: en primer lugar, se casa parcialmente la sentencia por la violación directa de la ley sustancial y, en segundo lugar, se anula el fallo dada la indebida motivación.

En esta breve reseña vamos a hacer una muy breve consideración en lo que toca con el argumento que lleva a la Corte a casar la sentencia y que se vincula con la interpretación y análisis del delito de omisión de agente retenedor.

Se requiere tener como punto de partida la premisa según la cual el delito de omisión de agente retenedor se encuentra con una realidad que existe por virtud del Derecho Tributario. Esto es, la protección penal debe elaborarse con fundamento en presupuestos que tienen su origen en el Derecho Tributario. Entre los presupuestos que es necesario considerar de forma que pueda elaborarse una adecuada

18 "De esta manera, refulge diáfano que como lo denuncia el demandante en el primer cargo, en la sentencia de primer grado hubo falta de motivación ya que no se dio contestación a los pedimentos defensivos, cuando uno de los controles a la actividad jurisdiccional, el artículo 55 de la Ley Estatutaria de la Administración de Justicia (Ley 270 de 1996), impone a los jueces el deber de abordar en las sentencias "todos los hechos y asuntos planteados en el proceso por los sujetos procesales»", Ibíd., pp. 33 y 34.

19 "Aquí no se trataba de un tema nimio que se considerara integrado en el texto de la decisión, sino que al ponerse de presente el pago de la obligación por concepto de Retención en la Fuente implicaba el estudio de las previsiones del parágrafo del artículo 402 del Código Penal relacionado con la exoneración de responsabilidad penal por tal causa", Ibíd., p. 34.

20 "De otro lado, al tener éxito el primer cargo, se declarará la nulidad parcial de la actuación desde el fallo de primer grado en lo concerniente a la Retención en la Fuente, debiendo retornar el diligenciamiento al juzgado a fin de que se dé respuesta a los pedimentos del vocero y del defensor del enjuiciado", Ibíd., p. 37. 
interpretación y aplicación del tipo penal está el bien jurídico, el sujeto activo y, entre muchos otros, un elemento que permite vincularse a la norma penal primaria preceptiva que da lugar al mandato cuyo incumplimiento permite acreditar que se ha realizado la omisión sancionada en el delito de omisión de agente retenedor. En otros términos, este delito requiere de una remisión al Derecho Tributario de manera que pueda elaborarse un elemento básico del tipo de omisión pura, cual la precisión de la acción determinada.

En la redacción del tipo de omisión de agente retenedor se desprende una norma preceptiva cuyo contenido ordena consignar las "sumas retenidas 0 autorretenidas" por concepto de retención en la fuente, o las sumas "recaudadas" por impuesto sobre las ventas. Conforme el punto de partida antes asumido, se tiene que no es posible precisar, sin recurrir al Derecho Tributario, aquello que el sujeto está obligado a consignar. Así, aquello a que está obligado el sujeto activo no es otra cosa que el presupuesto típico que en Derecho Tributario da origen al impuesto sobre las ventas 0 a la retención en la fuente, presupuesto que como bien se indica en la sentencia de casación ni es la liquidación oficial realizada por la DIAN ni mucho menos en la sanción que se impone por virtud del artículo 651 del Estatuto tributario. Es decir, la obligación de consignar recae sobre el presupuesto generador de la obligación Tributaria como hecho imponible tipificado por el Derecho Tributario. En consecuencia, razón tiene al afirmar que la suma que debe consignarse y cuya omisión se sanciona penalmente sólo puede ser la correspondiente a la que tiene origen en el hecho imponible. Así las cosas, la interpretación de instancia efectivamente extiende el ámbito del tipo más allá de la remisión normativa del delito de omisión de agente retenedor, incluyendo no el valor producto del hecho imponible, sino la suma producto de la sanción tributaria.

Adicionalmente, el razonamiento de instancia, al que con razón se opone la Corte, conlleva el desconocimiento del principio de lesividad concretado en que toda intervención penal debe estar dirigida a la protección del bien jurídico penalmente protegido por la ley. La interpretación propuesta por las sentencias de instancia desconoce este principio, en la medida en que avala el recurso al ius puniendi para garantizar el cumplimiento de una sanción administrativa, en este caso la sanción tributaria, lo que es muy diferente a garantizar el bien jurídico tutelado por el delito de omisión de agente retenedor que a juicio de la jurisprudencia es la administración pública²1.

21 Así, las sentencia de la Corte Suprema de Justicia de 11 de diciembre de 2013, radicado 33.468, ponente Eugenio Fernández Carlier; de 11 de noviembre de 2009, radicado 32116, ponente María del Rosario González de Lemos y de 30 de enero de 2008, radicado 25.818, ponente maría del Rosario González de Lemos. 